\title{
PbO-Grafen Elektrot Yüzeyinde Askorbik Asit ile Dopaminin Eşzamanlı Elektrokimyasal Tespiti
}

\author{
Simultaneous Electrochemical Detection of Ascorbic Acid and Dopamine on PbO- \\ Graphene Electrode
}

\author{
Bingül KURT URHAN ${ }^{1, a}$, Tuba ÖZNÜLÜER ÖZER ${ }^{2, b}$, Hülya ÖZTÜRK DOĞAN ${ }^{* 3, c}$ \\ ${ }^{1}$ Atatürk Üniversitesi, Fen Bilimleri Enstitüsü, Nanobilim ve Nanomühendislik Bölümü, Erzurum, Türkiye \\ ${ }^{2}$ Atatürk Üniversitesi, Fen Fakültesi, Kimya Bölümü, Erzurum, Türkiye \\ ${ }^{3}$ Atatürk Üniversitesi, Erzurum Meslek Yüksek Okulu, Kimya ve Kimyasal İşleme Teknolojileri Bölümü, Erzurum, Türkiye
}

•Geliş tarihi / Received: 31.01 .2019 •Düzeltilerek geliş tarihi / Received in revised form: 10.07.2019 • Kabul tarihi / Accepted: 04.08.2019

\begin{abstract}
$\ddot{O} z$
$\mathrm{Bu}$ çalışmada, kurșun oksit-grafen (PbO-G) nanokompozitlerinin $\mathrm{Au}$ elektrot yüzeyinde katodik elektrodepozisyonu; yeni bir elektrokimyasal metot kullanılarak $\mathrm{Pb}+2$ ve grafen oksit ihtiva eden aynı çözelti içerisinde, sabit tek bir potansiyelde gerçekleştirildi. Elde edilen kompozit malzemenin morfolojik ve yapısal özelliklerini analiz etmek için XRD, XPS, SEM ve EDS spektroskopisi teknikleri kullanıldı. PbO-G nanokompoziti askorbik asit (AA) ile dopaminin (DA) eşzamanlı elektrokimyasal tespiti için çıplak Au ve PbO-modifiye edilmiș Au elektrotlardan daha yüksek bir akım yoğunluğu ve daha düşük oksidasyon potansiyeli gösterdi. Ayrıca DA'in $\mathrm{PbO}-\mathrm{G}$ elektrot yüzeyinde amperometrik tayini incelendi ve $0.5 \mu \mathrm{M}$ ile $100 \mu \mathrm{M}$ arasındaki doğrusal aralıkta tayin sınırı (sinyal/gürültü oranı=3 için) $0.001 \pm 0.00028 \mu \mathrm{M}$ olarak hesaplandı. PbO-G nanokompozit modifiye elektrot, AA varlığında DA'in elektrokimyasal tespiti ve amperometrik tayini için yeni, basit ve düşük maliyetli bir analiz yöntemi sağlamaktadır.
\end{abstract}

Anahtar kelimeler: Askorbik asit, Dopamin, Grafen, Grafen oksit, Kurşun oksit

\begin{abstract}
In this study, cathodic electrodeposition of lead oxide-graphene ( $P b O-G)$ nanocomposites on Au electrode surface was carried out by a new one-pot electrochemical method in the same solution containing $P b+2$ and graphene oxide. XRD, $X P S, S E M$, and EDS spectroscopy techniques were employed to analyze the morphological and structural characteristics of the composite materials. For simultaneous electrochemical detection of ascorbic acid (AA) and dopamine (DA), the PbO-G nanocomposite exhibited a higher current density and lower oxidation potential than the bare $\mathrm{Au}$ and $\mathrm{PbO}$-modified Au electrodes. Also, the amperometric detection of dopamine on PbO-G electrode surface was investigated and the limit of detection was estimated as $0.001 \mu \mathrm{M}$ in the linear range from $0.5 \mu \mathrm{M}$ to $100 \mu \mathrm{M}$ (at a signal-to-noise ratio of 3.0). This PbO-G nanocomposite-modified electrode provided a novel, simple, and low-cost route for the electrochemical detection and amperometric sensing of DA in the presence of $A A$.
\end{abstract}

Keywords: Ascorbic acid, Dopamine, Graphene, Graphene oxide, Lead oxide

\footnotetext{
*cHülya Öztürk Doğan, hdogan@atauni.edu.tr, Tel:(0442) 231 2636, orcid.org/0000-0002-4072-7744

a orcid.org/0000-0002-8742-6789 b orcid.org/0000-0001-5148-2984
} 


\section{Giriş}

Askorbik asit (AA) ve dopamin (DA) merkezi sinir, böbrek ve hormonal sistemlerde önemli bir rol oynamaktadır (Gopalan vd., 2007; Wang vd., 2009). Vücutta bu maddelerin eksikliği kanser, Parkinson hastalığı ve kardiyovasküler hastalıklar gibi birçok kötü hastalığın semptomlarına yol açabilmektedir (Hu vd., 2009). Bununla birlikte, AA ve DA'in elektrokimyasal aktivitelerinin bulunmas1, AA ve DA tespitinde elektroanaliz yöntemlerine olan ilgiyi arttırmıştır. Bununla birlikte, DA ile AA metabolik sistemde birlikte bulunmas1 ve elektrokimyasal tespitte oksidasyon potansiyellerinin birbirine oldukça yakın olması potansiyometrik olarak ayrılmalarını güçleştirir
(Wang vd., 2009; Hu vd., 2009). Bu problemin üstesinden gelmek için karbon nanotüpler, karbon nanofiberler ve grafen $(G)$ de dahil olmak üzere çeşitli karbon bazlı malzemeler ile iletken polimerler, metaller veya metal oksitler kullanılarak hazırlanan modifiye elektrotlar sayesinde oksidasyon potansiyellerinin birbirinden ayrılması hedeflenmiştir (Palanisamy vd., 2013). Son zamanlarda, grafen tabanl1 elektrokimyasal sensörler DA'nın elektrokatalitik oksidasyonu için yaygin olarak kullanılmaktadırlar (Wang vd., 2009; Kim vd., 2010; Sun vd., 2011; Palanisamy vd., 2013; Wang vd., 2014). DA ve AA yapıları Şekil 1'de verilmiştir.

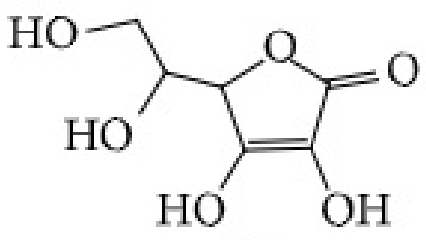

AA

Şekil 1. Dopamin ve askorbik asit yapıları

Kurşun oksit, oksidasyon durumuna bağl1 olarak $\mathrm{PbO}, \mathrm{PbO}_{2}, \mathrm{~Pb}_{2} \mathrm{O}_{3}$ ve $\mathrm{Pb}_{3} \mathrm{O}_{4}$ olmak üzere dört formda bulunur (Mizoguchi vd., 1996; Li vd., 2012). Bu formlar arasında, kurşun (II) oksit $(\mathrm{PbO})$, optoelektronik özellikleri nedeniyle dikkat çekicidir (Kwon vd., 2011). Saf $\mathrm{PbO} ; \mathrm{Pb}_{3} \mathrm{O}_{4}$, $\mathrm{Pb}_{2} \mathrm{O}_{3}$ ve $\mathrm{Pb}_{12} \mathrm{O}_{19}$ gibi farklı kurşun bileşiklerinin termal ayrışmasıyla üretilebilmektedir (Sajadi, 2011). Literatürde $\mathrm{PbO}$ üretimi için termal birikim, sonokimyasal biriktirme, sprey piroliz, ve elektrodepozisyon teknikleri kullanılmıştır (Konstantinov vd., 2006). Elektrokimyasal depozisyon, kristalin ince filmlerin ve yüksek kaliteli elektrokimyasal biriktirilmiş malzemelerin, 1sıl işlem olmaksızın oda sıcaklığında doğrudan oluşumuna yol açar (Dan vd., 2012). Diğer kurşun oksitler ile karşılaştırıldığında $\mathrm{PbO}_{2}$ kapsamlı bir şekilde araştırılmışken, sadece birkaç çalışma $\mathrm{PbO}^{\prime}$ in elektrokimyasal sentezini bildirmiştir (Zhitomirsky vd., 1995) ve hem $\mathrm{PbO}$ hem de $\mathrm{PbO}$ kompozitlerinin analitik uygulamaları da son derece sinırlıdır. $\mathrm{Mn}^{+2}$ dedeksiyonu için Velayutham ve Noel (1992), $\mathrm{Pb}\left(\mathrm{CH}_{3} \mathrm{COO}\right)_{2}$ içeren $\mathrm{KNO}_{3}$ çözeltisinden sabit potansiyel elektrolizi yöntemini kullanarak polipirol/kurşun oksit kompozit elektrot hazırladilar. Ayrica, PbO'in bakır (Shahid vd., 2011; Li vd., 2015), polianilin (Parveen vd., 2013), grafit (Pan vd., 2009) ve amorf karbon ( $\mathrm{Ng}$ vd., 2006) ile oluşturulan nanokompozit elektrot malzemeleri de literatürde mevcuttur. Ramesha ve Sampath (2011), cams1 karbon elektrot üzerinde grafen oksit/PbO kompozitini, iki aşamalı bir elektrokimyasal yöntemle sentezlemiştir. Bununla birlikte, PbO-G film-modifiye edilmiş $\mathrm{Au}$ elektrodun doğrudan tek potansiyelde elektrokimyasal sentezi ve biyosensör uygulamaları literatürde şimdiye kadar bildirilmemiştir. $\mathrm{Bu}$ çalışmada, $\mathrm{PbO}-\mathrm{G}$ hibrit film elektrotlar sabit tek bir potansiyel uygulanarak elektrokimyasal teknik ile başarılı bir şekilde üretilmiş ve AA varlığında DA'in elektrokimyasal tespitinde elektrot malzemesi olarak kullanılmıştır.

\section{Deneysel Çalışmalar}

PbO-G nanokompozit elektrotların elektrokimyasal sentezi BAS100i potansiyostat cihazı kullanılarak gerçekleştirilmiştir. Üç elektrotlu hücre sisteminde çalışma elektrodu olarak $\mathrm{Au}$, karşıt elektrot olarak Pt tel ve referans elektrot olarak ise $\mathrm{Ag} / \mathrm{AgCl} \quad(3 \mathrm{M} \quad \mathrm{KCl})$ kullanılmıştır. PbO-G kompozitleri -600 mV'ta 1 dakika süre ile depozisyon yapılarak hazırlanmıştır. Elektrokimyasal sentez prosesi Şekil 2'de şematik olarak gösterilmiştir: 


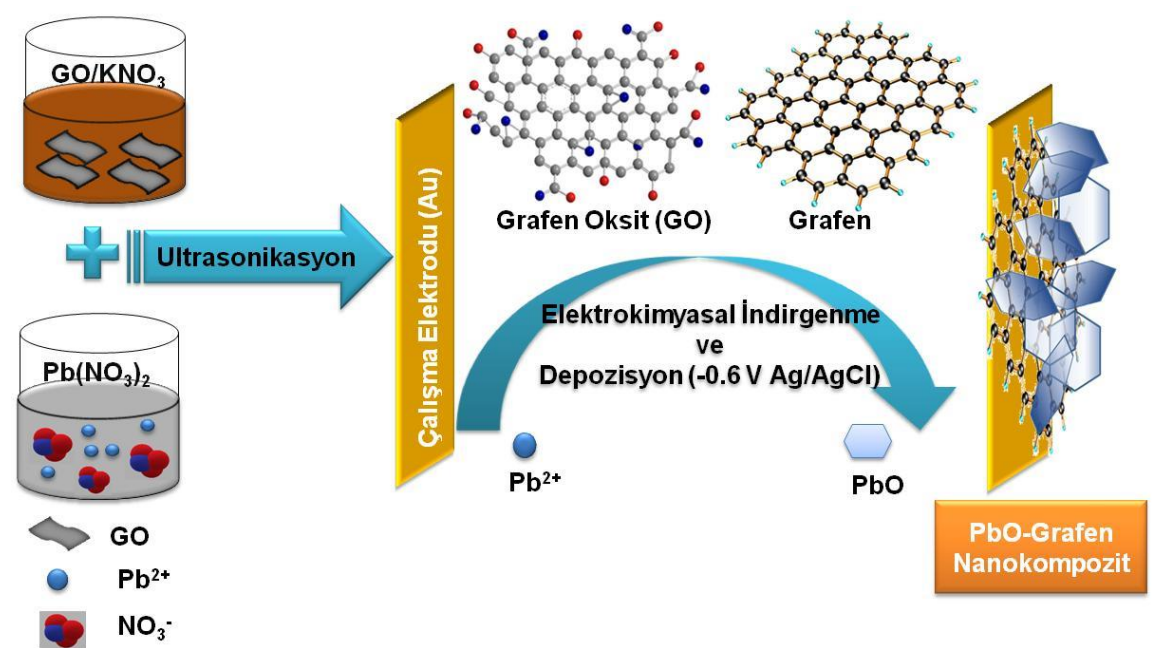

Şekil 2. PbO-grafen nanokompozitinin elektrokimyasal sentezinin şematik gösterimi

Deneylerde kullanılan grafen oksit (GO), kurşun nitrat $\left(\mathrm{Pb}\left(\mathrm{NO}_{3}\right)_{2}\right)$, dopamin (DA), askorbik asit (AA), sodyum dihidrojen fosfat $\left(\mathrm{NaH}_{2} \mathrm{PO}_{4}\right)$ ve disodyum hidrojen fosfat $\left(\mathrm{Na}_{2} \mathrm{HPO}_{4}\right)$ kimyasallar1 Sigma-Aldrich firmasindan alındı. 0.1 M fosfat tamponu (PBS, pH 7.0) içinde $10 \mathrm{mM}$ DA stok çözeltisi hazırlandı ve $4{ }^{\circ} \mathrm{C}$ 'de muhafaza edildi.

PbO-G nanokompozitlerinin karakterizasyonu, taramalı elektron mikroskobu (SEM, FEI Quanta), enerji dağılım spektroskopisi (EDS, FEI Quanta ile birleştirilmiş), X-ray fotoelektron spektroskopisi (XPS, PHI 5000 VersaProbe) ve $\mathrm{X}$-ışınları kırınım spektroskopisi (XRD, Rigaku Advance) teknikleri kullanılarak gerçekleştirilmiştir.

\section{Bulgular ve Tartışma}

\subsection{PbO-G Nanokompozitlerinin Karakterizasyonu}

GO ve $\mathrm{Pb}^{+2}$ karışım çözeltisinden 1 dakika süre ile $-600 \mathrm{mV}$ 'ta sentezlenen kompozit filmin kristal yapısını karakterize etmek için XRD tekniği kullanıldı. Kompozit filmin tek basamaklı elektrokimyasal sentezinde çıkış maddesi olarak grafen oksit (GO) kullanılmıştır. GO elektrokimyasal indirgenme sonrasinda grafen $(\mathrm{G})$ yapısına dönüşmektedir. Bu dönüşümün kompozit yapıda da gerçekleştiğini karşılaştırmak amacıyla XRD spektrumları aynı grafikte gösterildi (Şekil 3a). GO'e karşılık gelen karakteristik kırınım piki $2 \theta=11.1^{\circ}$ 'de gözlenmektedir. Elektrokimyasal indirgemeden sonra GO'e karşılık gelen pik tamamen ortadan kaybolmuş ve $\sim 24.4^{\circ}$ de $\mathrm{G}$ yapısına ait yeni bir kırınım piki ortaya çıkmıştır.
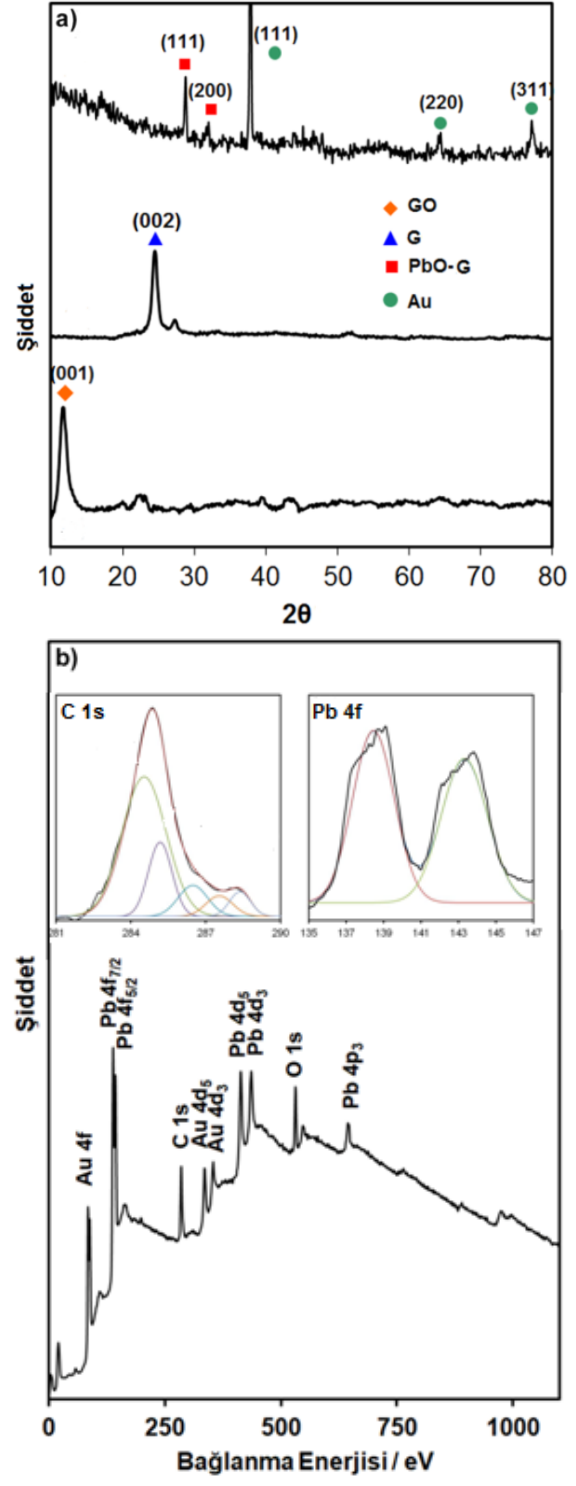

Şekil 3. a) $\mathrm{GO}, \mathrm{G}$ ve $\mathrm{PbO}-\mathrm{G}$ nanokompozitinin XRD spektrumları, b) PbO-G nanokompozitinin genel tarama XPS spektrumu (iç grafikler $\mathrm{C} 1$ s ve $\mathrm{Pb} 4 \mathrm{f}$ XPS spektrumları) 
$\mathrm{Bu}$ pik, literatürde grafitin (002) kristal yapısı için elde edilen ile oldukça uyumludur (Wang vd., 2012).

Kompozit filmin XRD spektrumunda ise $\mathrm{PbO}$ ve $G$ piklerinin yanı sira substrat olmasından kaynaklı Au'na ait kırınım pikleri de gözlenmiştir. $\mathrm{PbO}-\mathrm{G}$ için $2 \theta=28.6^{\circ}$ ve $32.6^{\circ}$ 'da gözlenen iki ana karakteristik pik sirasiyla $\mathrm{PbO}$ 'in (111) ve (200) Miller indekslerine karşıllk geldiği belirlenmiştir (JCPDS CAS no. 1317-36-8) (Stillman vd., 1984). $\mathrm{G}$ içeren kompozitlerde artan düzensiz istiflenmenin ve $G$ tabakalarını daha az aglomerasyonunun bir sonucu olarak; G tabakaları birbirlerinden uzaklaşmakta ve G'e ait XRD kırınım pik şiddeti daha küçük olmaktadır (Chen vd., 2011). Hatta XRD spektrumunda G piki gözlenememektedir (Wang vd., 2016). Bu duruma benzer davranış PbO-G kompozitine ait XRD spektrumunda da tespit edilmiştir.
Kompozit malzemedeki metal oksit ve karbon yapılarına ait bağlanma enerjileri XPS spektroskopisi tekniği kullanılarak ölçülmüştür. XPS spektrumunda; $\mathrm{Pb}$ 4f bölgesine ait bağlanma enerjisi değerleri Pb'un metalik veya oksit formunda olduğu hakkında bilgi verir. Metalik $\mathrm{Pb}$ için $4 f_{5 / 2}$ ve $4 f_{7 / 2}$ pikleri sırasiyla 142.0 ve 137.3 $\mathrm{eV}$ değerindedir. $\mathrm{PbO}$ yapısındaki $\mathrm{Pb}$ pikleri ise $4 \mathrm{f}_{5 / 2}$ için 143.5 ve $4 \mathrm{f}_{7 / 2}$ için 138.6 eV'ta gözlenir. Şekil 3b'de verilen XPS spektrumundaki $\mathrm{Pb}$ pikleri tamamen $\mathrm{PbO}$ yapisi ile uyumludur. Ayrıca karbon (C) bölgesine ait spektrum incelendiğinde; GO yapısındaki oksijen içeren fonksiyonel gruplara ait 285-289 eV arasindaki pik şiddetleri elektrokimyasal indirgenme ile azalarak $\mathrm{C}=\mathrm{C}$ çift bağına dönüşüm gerçekleşmiştir. XRD ve XPS spektrumlarına göre sabit tek potansiyel depozisyon yöntemi kullanilarak $\mathrm{PbO}-\mathrm{G}$ nanokompozitlerinin elektrokimyasal olarak sentezlenebileceği görülmektedir.

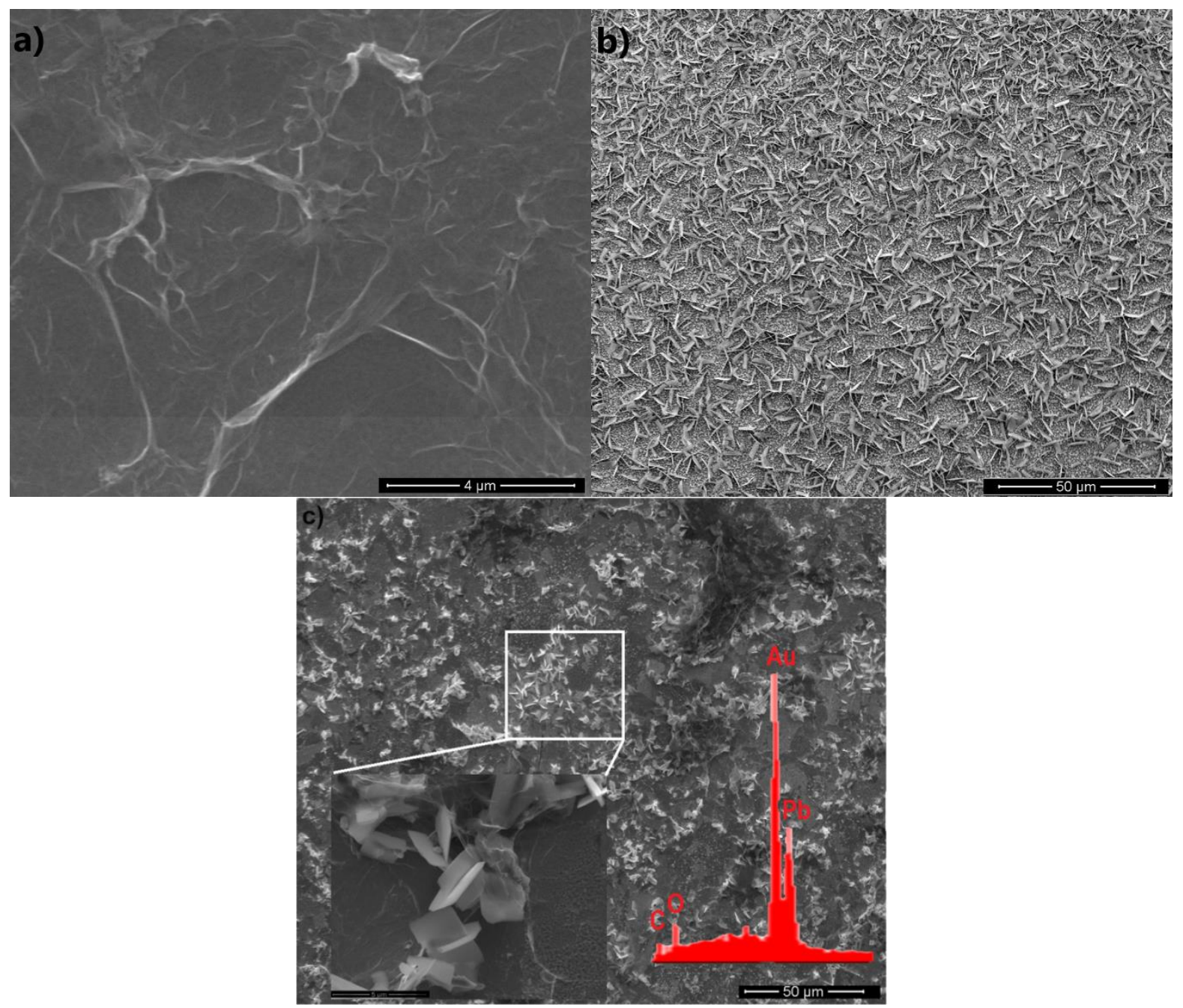

Şekil 4. a) $\mathrm{G}$, b) $\mathrm{PbO}$ ve c) $\mathrm{PbO}-\mathrm{G}$ nanokompozitinin $\mathrm{SEM}$ görüntüleri (c iç şekiller: $\mathrm{PbO}-\mathrm{G}$ nanokompozitinin 20000x büyütme oranında alınmış SEM görüntüsü ve EDS spektrumu). 
Oldukça düz ve tanımlı bir yüzeye sahip Au elektrodun $\mathrm{PbO}-\mathrm{G}$ nanokompoziti ile modifikasyonunu morfolojik olarak incelemek amacıyla SEM görüntüleri alınmıştır. Bu amaçla $\mathrm{Au}$ elektrotlar öncelikle sadece $\mathrm{G}$ ve sadece $\mathrm{PbO}$ yapıları ile kaplanmıştır (aynı deneysel şartlar altında hazırlanan numuneler kullanılmıştır). Şekil 4a'da $A u$ yüzeyi sadece $G$ tabakası ile modifiye edilmiş ve G'nin kıvrımlı çarşafımsı yapısı oldukça net bir şekilde görülmüştür. GO içermeyen çözeltiden $\mathrm{PbO}$ elde edebilmek amacıyla $\mathrm{Pb}^{+2}$ çözeltisinden sabit akış hızında oksijen gazı geçirilmiştir. Şekil 4b'de sadece $\mathrm{PbO}$ tabakasına ait alınan SEM görüntüsünde $\mathrm{PbO}$ 'in palet yapıları net bir şekilde görülebilmektedir. Şekil 4c, Au elektrodu üzerinde biriktirilen PbO$G$ kompozit filmlerin SEM görüntülerini göstermektedir. $\mathrm{PbO}-\mathrm{G}$ 'in $\mathrm{SEM}$ görüntüsünde de $\mathrm{G}$ tabakasının oldukça ince, kıvrımlı ve buruşuk morfolojiye sahip olduğu belirlenmiştir. Kompozit için alınan 1200x büyütmeli SEM görüntüsünde yüzeyin kompozit film ile tamamen kaplandığ1 ve G yüzeyinde herhangi bir agregasyon olmadan $\mathrm{PbO}$ paletlerinin homojen olarak dağıldığ görülmektedir. Şekil 4c'de iç resim olarak verilen 20000x büyütmeli SEM görüntüsü, PbO parçacıklarının ortalama $3 \mu$ m'lik bir parçacık boyutuna sahip palet şeklinde olduğunu gösterir.

\subsection{PbO-G Elektrotta Askorbik Asit Varlı̆̆ında Dopaminin Elektrokimyasal Davranışı}

DA elektrokimyasal olarak yükseltgenebilen bir madde olup, yükseltgenme tepkimesi Şekil 5'te verilmiştir. Biyolojik ve farmasotik olarak oldukça önemli olan DA ve AA'in elektrokimyasal davranışlarına karşı Au elektrotun katalitik aktivitesini geniş ölçüde değiştirebilmek amaciyla, $\mathrm{Au}$ elektrot $\mathrm{PbO}$ ve $\mathrm{PbO}-\mathrm{G}$ kompoziti ile modifiye edildi.

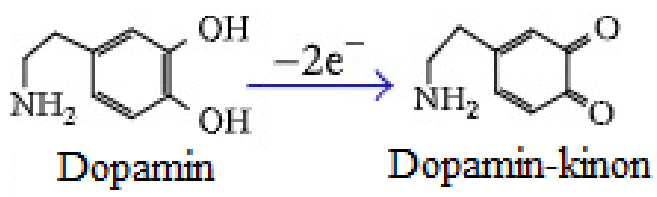

Şekil 5. Dopaminin elektrokimyasal yükseltgenme tepkimesi

10.0 mM DA içeren $0.1 \mathrm{M}$ fosfat tamponunda (PBS) çıplak $\mathrm{Au}, \mathrm{PbO}$-modifiye edilmiş $\mathrm{Au}(\mathrm{Au}-$ $\mathrm{PbO}$ ) ve $\mathrm{PbO}-\mathrm{G}$ kompoziti modifiye $\mathrm{Au}(\mathrm{Au}-\mathrm{PbO}-$ G) elektrotların $50 \mathrm{mV} / \mathrm{s}$ tarama hızında kaydedilen dönüşümlü voltamogramları Şekil 6a'da karşılaştırılmıştır.
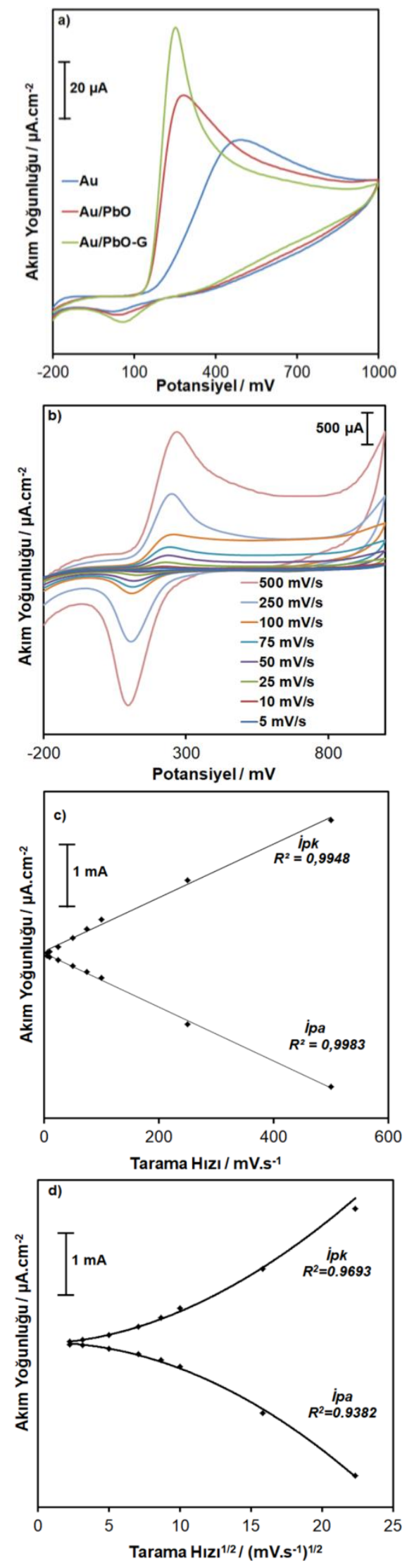

Şekil 6. a) $\mathrm{Au}, \mathrm{Au}-\mathrm{PbO}$ ve $\mathrm{Au}-\mathrm{PbO}-\mathrm{G}$ elektrotların 10 $\mathrm{mM} \quad \mathrm{DA} / 0.1 \quad \mathrm{M}$ PBS çözeltisindeki dönüşümlü voltamogramları, b) Au-PbO-G elektrodunun DA çözeltisinde farklı tarama hızlarında alınan dönüşümlü voltamogramları ve c) Au-PbO-G elektrodu için anodik ve katodik pik akım yoğunlukları-tarama hızı grafikleri 
$\mathrm{Bu}$ voltamogramlarda hem oksidasyon potansiyelinin daha düşük değerde olması ( 200 $\mathrm{mV}$ ) hem de daha yüksek akım yoğunluğunun $\left(\sim 2.2 \mathrm{~mA} . \mathrm{cm}^{-2}\right)$ elde edilmesinden dolayi; PbO-G modifiye elektrot $\mathrm{Au}$ ve $\mathrm{Au}-\mathrm{PbO}$ ile karşılaştırıldığında DA sensörü için daha uygun bir materyaldir.

PbO-G modifiye elektrot için DA çözeltisinde 5, $10,25,50,75,100,250$ ve $500 \mathrm{mV} / \mathrm{s}$ tarama hızlarında voltamogramlar alınmıştır (Şekil 6b). $\mathrm{Bu}$ voltamogramlarda tarama hizının artması ile oksidasyon pik potansiyeli pozitife kaymış ve pik akım yoğunluğu artmıştır. Katodik ve anodik pik akım yoğunlukları tarama hızına bağlı olarak grafik edildiğinde (Şekil 6c), artan tarama hızlarıyla redoks pik akımları doğrusal olarak orantılıdır. Randles-Sevcik eşitliğine göre DA'in yükseltgenmesinin difüzyon kontrollü olarak da gerçekleşebileceğini belirlemek için tarama hızının kareköküne karşılık akım yoğunluğu grafikleri çizilmiştir (Şekil 6d). Şekil 6d'de verilen grafiklerin doğrusal bir değişim vermediği tespit edilmiştir. $\mathrm{Bu}$ sonuçlar, $\mathrm{PbO}-\mathrm{G}$ modifiye elektrotta DA'in elektrokimyasal oksidasyonunun tipik bir yüzey adsorpsiyon kontrollü süreç olduğunu ortaya koymaktadır.

10.0 mM AA içeren 0.1 M PBS ortamında $\mathrm{Au}$, $\mathrm{Au}-\mathrm{PbO}$ ve Au-PbO-G elektrotlarm $50 \mathrm{mV} / \mathrm{s}$ tarama hızında kaydedilen dönüşümlü voltamogramları Şekil 7a'da gösterilmiştir. Yaklaşı $100 \mathrm{mV}$ 'ta belirgin bir oksidasyon piki gözlenmiştir. DA ortamında alınan voltamograma benzer şekilde PbO-G kompoziti en iyi elektrokatalitik özellik sergilemiştir.
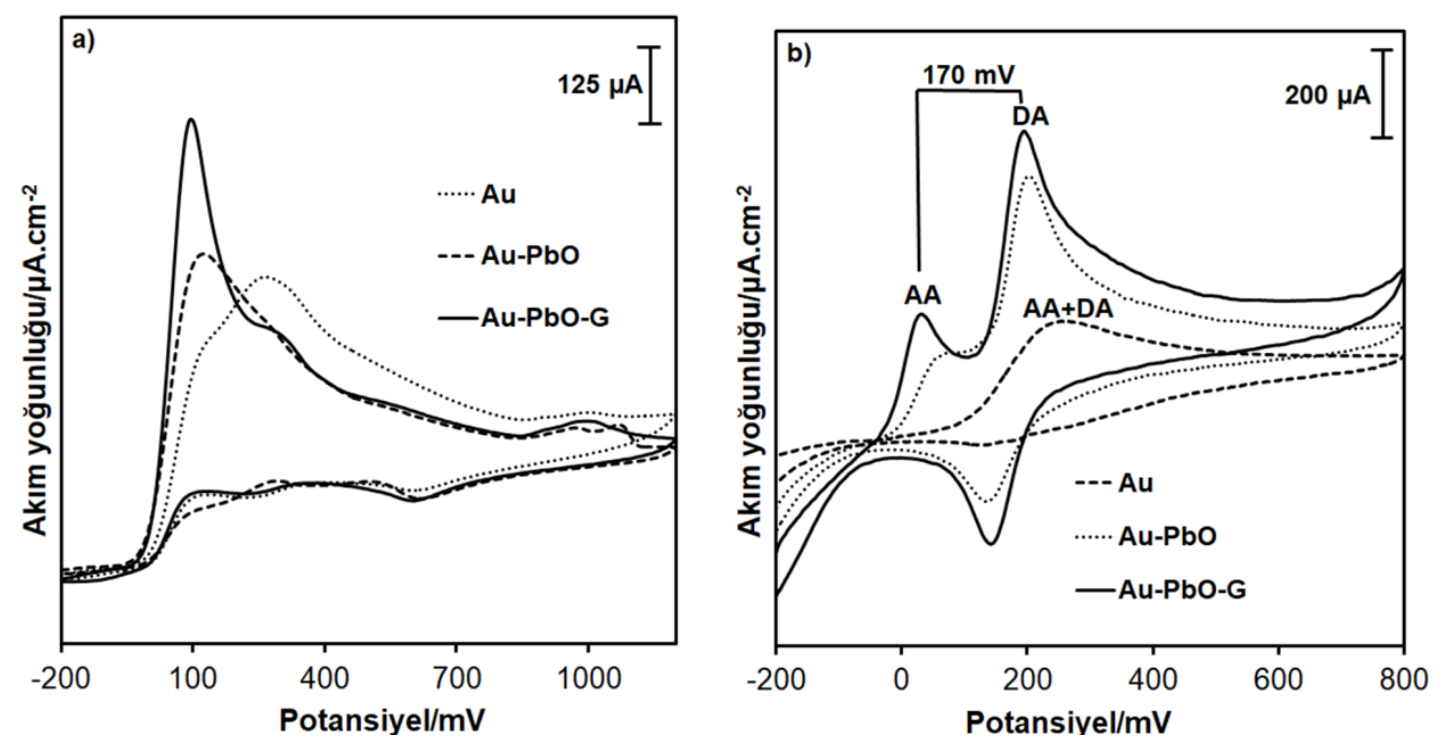

Şekil 7. Au, Au-PbO ve Au-PbO-G elektrotların a) 10 mM AA/0.1 M PBS çözeltisindeki dönüşümlü voltamogramları ve b) $1 \mathrm{mM}$ DA ve $100 \mathrm{mM}$ AA içeren karışım çözeltisindeki voltamogramları

Biyolojik sistemlerde DA'in tespiti AA varlı̆̆ında zorlaşmaktadır. Vücut ortamında AA'in miktarca daha fazla bulunması DA'e duyarlı sensör gelişimini zorunlu kılmaktadır. Bu amaçla $1 \mathrm{mM}$ DA ve 100 mM AA içeren çözelti ortamında Au, $\mathrm{Au}-\mathrm{PbO}$ ve $\mathrm{Au}-\mathrm{PbO}-\mathrm{G}$ elektrotların elektrokimyasal davranışları incelenmiştir (Şekil 7b). Modifiye edilmemiş Au elektrot karışım çözeltisinde DA ve AA'in ayrı ayrı tespitini gerçekleştirememektedir. Ancak $\mathrm{PbO}$ ve $\mathrm{PbO}-\mathrm{G}$ kompozitinin modifiyesi $\mathrm{Au}$ elektrodun her iki maddeye de spesifik olarak cevap vermesine katk1 sağlamış ve her iki türe ait iki farklı pik gözlenmesine neden olmuştur. Ayrıca PbO-G kompoziti için DA ve AA'ya ait oksidasyon pik akım yoğunlukları daha fazla olup, her iki maddenin oksidasyon potansiyeli arasında 170 $\mathrm{mV}$ fark gözlenmiştir.

DA'in farklı konsantrasyonlarının ardışık bir şekilde karıştırılan 0.1 M PBS çözeltisine eklenmesiyle ortaya çıan tipik akım-zaman $(i-t)$ eğrisi Şekil 8'de verilmiştir. pH 7 çözeltisine DA eklendikten sonra, katodik akım yoğunluklarının sabit bir değere ulaşmak için adım adım arttığı görülmüştür. Nanokompozit elektrotta, elektrokatalitik cevabın hızlı olduğunun kanıtı olarak 5 saniyeden daha kisa bir zamanda neredeyse sabit bir akım elde edilebilmiştir. 


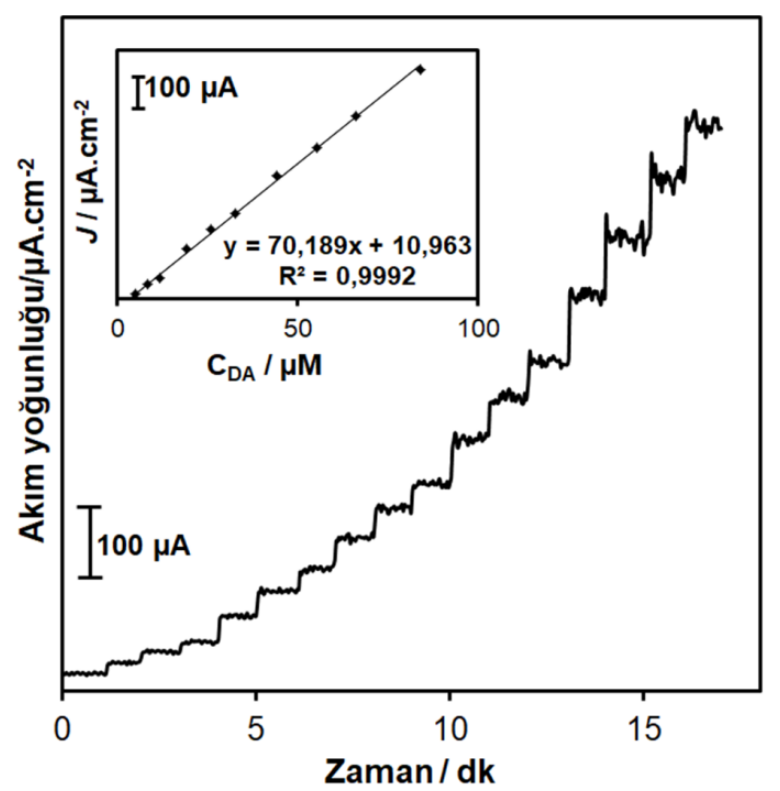

Şekil 8. Au-PbO-G elektrodunun $\mathrm{pH} 7$ fosfat tamponuna farklı konsantrasyonlarda DA eklenmesine ait amperometrik cevabı (iç grafik: kalibrasyon eğrisi).

PbO-G kompozitinin DA'in farklı konsantrasyonlarında eklenmesine verdiği tipik amperometrik cevap incelendiğinde özellikle düşük konsantrasyon aralığında (Şekil 8 iç grafik), hizlı bir amperometrik cevap \%96'l1k sabit hal akımı gözlenmiştir. DA biyosensörü için kompozit malzemenin $70 \mu \mathrm{A} \quad \mathrm{cm}^{-2} \mathrm{mM}^{-1}$ 'lik yüksek bir hassasiyete sahip olduğu ve $0.5 \mu \mathrm{M}$ ile $100 \mu \mathrm{M}$ 'lık bir konsantrasyon aralığında da lineer bir ilişki $(\mathrm{R}=0.9992)$ gösterdiği yapılan hesaplamalar sonucunda bulunmuştur. İlaveten, sinyal-gürültü oranı 3 olduğunda tayin sınırı yaklaşı $\quad 0.001 \pm 0.00028 \quad \mu \mathrm{M} \quad$ olarak hesaplanmıştır. Literatürde daha önce farklı elektrotlarda hesaplanan tayin sinırları Tablo 1'de karşılaştırılmıştır. $\quad \mathrm{Bu}$ elektrotlarla kıyaslandığında; nispeten daha düşük tayin sinırına sahip olmasindan dolayı Au-PbO-G elektrot DA' in amperometrik tayininde başarılı bir şekilde kullanılabilir.

Tablo 1. Farklı elektrotların DA’in amperometrik tayini için karşılaştırması

\begin{tabular}{cccc} 
Elektrot & Lineer Aralık $(\mu \mathrm{M})$ & Tayin sinırı $(\mu \mathrm{M})$ & Referans \\
\hline \hline AuNCs/G/MWCNT & $1-210$ & 0.08 & (Abdelwahab vd., 2015) \\
rGO-CDs/GCE & $0.01-450$ & 0.015 & (Hu vd., 2014) \\
$\mathrm{Au}-\mathrm{Pt} / \mathrm{GO}-\mathrm{ERGO}$ & $0.06-498$ & 0.02 & (Liu vd., 2015) \\
$\mathrm{Fe}_{3} \mathrm{O}_{4} / \mathrm{rGO} / \mathrm{GCE}$ & $0.4-3,5$ & 0.08 & (Teymourian vd., 2013) \\
$\mathrm{Au} / \mathrm{rGO} / \mathrm{GCE}$ & $6.8-41$ & 1.4 & (Wang vd., 2014) \\
$\mathrm{Cu}{ }_{2} \mathrm{O} / \mathrm{G}$ & $0.1-10$ & 0.01 & (Zhang vd., 2011) \\
$\mathrm{Au}-\mathrm{PbO}-\mathrm{G}$ & $0.5-100$ & 0.001 & Bu çalışma
\end{tabular}

NCs; Nanokümeler, G; grafen, MWCNT; Çok duvarlı karbon nanotüp, rGO; indirgenmiş grafen oksit, CDs; Karbon parçacıklar; GCE; Camsı karbon elektrot, GO; Grafen oksit; ERGO; elektrokimyasal indirgenmiş grafen oksit.

Son olarak, PbO-G elektrotlar DA'in insan kan serum numunelerinde analizi için kullanıldı. Bu amaçla birden fazla defa (ölçüm sayısı=3) amperometrik tayin tekrar edilmiş; kalibrasyon eğrisi kullanılarak DA konsantrasyonları hesaplanmış ve sonuçlar Tablo 2'de karşılaştırılmıştır. Aynı konsantrasyon değeri için kaydedilen akım yoğunluğu değerlerinin ortalaması alınarak standart sapma hesaplaması yapılmıştır. İnsan serum örnekleri için eklenen ve bulunan konsantrasyon değerleri karşılaştırıldığında; önerilen DA sensörünün kesin ve güvenilir olduğunu gösteren sonuçlar elde edildi. 
Tablo 2. İnsan kan serumu örneklerinde DA tayini $(\mathrm{n}=3)$

\begin{tabular}{cccc} 
Örnek & Eklenen $(\mu \mathrm{M})$ & Bulunan $(\mu \mathrm{M})$ & Geri kazanım $(\%)$ \\
\hline \hline 1 & 10.0 & $9.8 \pm 1.2$ & 98.0 \\
2 & 25.0 & $25.3 \pm 1.8$ & 101.2 \\
3 & 50.0 & $49.8 \pm 2.3$ & 99.6 \\
\hline
\end{tabular}

\section{Sonuç}

$\mathrm{Au}$ elektrot $\mathrm{Pb}^{+2}$ ve $\mathrm{GO}$ içeren çözelti karışımından sabit tek bir potansiyel uygulanarak başarılı bir şekilde PbO-G kompoziti ile modifiye edildi. Yapılan analitik ve morfolojik karakterizasyonlar kompozitin hem $\mathrm{PbO}$ hem de $\mathrm{G}$ içerdiğini destekledi. PbO-G modifiye edilen elektrot AA ile DA'in eşzamanlı olarak elektrokimyasal tespitinde kullanıldı. DA ve AA' in oksidasyon potansiyelindeki daha düşük enerjili bölgeye kayma ve akım yoğunluğundaki artış yönünden, en iyi elektrokatalitik aktivite $\mathrm{PbO}-\mathrm{G}$ kompoziti ile modifiye edilen $\mathrm{Au}$ elektrotta tespit edildi. Tek başına Au elektrot ve $\mathrm{Au}-\mathrm{PbO}$ elektrotla karşılaştırıldığında gelişmiş bu elektrokimyasal performansının nedeni olarak; her bir bileşenin kendi benzersiz özelliklerine kıyasla daha iyi özellikler sağlayan kompozit materyallerin sahip olduğu sinerjik etki gösterilebilir.

Özetle; yüksek etkin yüzey alanına sahip metal oksit gibi nanoparçacıklar ile grafenden oluşan kompozitler, analitik hassasiyeti artırmak amaciyla heterojen elektron transferini kolaylaştırmak ve biyolojik açıdan önemli olan bileşiklerin anlık belirlenmesi için elektrokatalitik reaksiyonlarda kullanılanılabilirler.

\section{Kaynaklar}

Abdelwahab, A.A. ve Shim, Y.B., 2015. Simultaneous determination of ascorbic acid, dopamine, uric acid and folic acid based on activated graphene/MWCNT nanocomposite loaded Au nanoclusters. Sensors and Actuators B: Chemical, 221, 659-665.

Chen, M., Park, C., Choi, J. ve Oh, W., 2011. Synthesis and characterization of metal ( $\mathrm{Pt}, \mathrm{Pd}$ and $\mathrm{Fe}$ )graphene composites. J.Korean Ceramic Soc., $48,147-151$.

Dan, Y.Y., Lin, H.B., Liu, X.L., Lu, H.Y., Zhao, J.Z., Shi, Z. ve Guo, Y.P., 2012. Porous quasi threedimensional nano- $\mathrm{Mn}_{3} \mathrm{O}_{4}+\mathrm{PbO}_{2}$ composite as supercapacitor electrode material. Electrochim Acta, 83, 175-182.

Gopalan, A.I., Lee, K., Manesh, K.M., Santhosh, P., Kim, J.H. ve Kang, J.S., 2007. Electrochemical determination of dopamine and ascorbic acid at a novel gold nanoparticles distributed poly(4aminothiophenol) modified electrode. Talanta, 71, 1774-1781.

Hu, G., Guo, Y. ve Shao, S., 2009. Simultaneous determination of dopamine and ascorbic acid using the nano-gold self-assembled glassy carbon electrode. Electroanalysis, 21, 12001206.

Hu, S., Huang, Q., Lin, Y., Wei, C., Zhang, H., Zhang, W., Guo, Z., Bao, X., Shi, J. ve Hao, A., 2014. Reduced graphene oxide-carbon dots composite as an enhanced material for electrochemical determination of dopamine. Electrochimica Acta, 130, 805-809.

Kim, Y., Bong, S., Kang, Y., Yang, Y., Kumar, R., Jong, M., Kim, S. ve Kim, H., 2010. Electrochemical detection of dopamine in the presence of ascorbic acid using graphene modified electrodes. Biosens. Bioelectron., 25, 2366-2369.

Konstantinov, K., Ng, S.H., Wang, J.Z., Wang, G.X., Wexler, D. ve Liu, H.K., 2006. Nanostructured $\mathrm{PbO}$ materials obtained in situ by spray solution technique for Li-ion batteries. J. Power Sources, 159, 241-244.

Kwon, Y., Lee, H. ve Lee, J., 2011. Autonomous interfacial creation of nanostructured lead oxide. Nanoscale, 3, 4984-4988.

Li, C.H., Sengodu, P., Wang, D.Y., Kuo, T.R. ve Chen, C.C., 2015. Highly stable cycling of a lead oxide/copper nanocomposite as an anode material in lithium ion batteries. Rsc Adv 5, 50245-50252.

Li, L., Zhu, X.F., Yang, D.N., Gao, L.X., Liu, J.W., Kumar, R.V. ve Yang, J.K., 2012. Preparation and characterization of nano-structured lead oxide from spent lead acid battery paste. J. Hazard. Mater. 203, 274-282.

Liu, Y., She, P., Gong, J., Wu, W., Xu, S., Li, J., Zhao, K. ve Deng, A., 2015. A novel sensor based on electrodeposited $\mathrm{Au}-\mathrm{Pt}$ bimetallic nano-clusters decorated on graphene oxide (GO)electrochemically reduced GO for sensitive detection of dopamine and uric acid. Sensors and Actuators B: Chemical, 221, 1542-1553.

Mizoguchi, H., Kawazoe, H. ve Hosono, H., 1996. Enhancement of electrical conductivity of polycrystalline beta- $\mathrm{PbO}$ by exposure to ozone 
gas at room temperature. Chem. Mater, 8, 27692773 .

Ng, S.H., Wang, J., Konstantinov, K., Wexler, D., Chen, J. ve Liu, H.K., 2006. Spray pyrolyzed $\mathrm{PbO}$-carbon nanocomposites as anode for lithium-ion batteries. J. Electrochem. Soc., 153, A787-A793.

Palanisamy, S., Ku, S. ve Chen, S., 2013. Dopamine sensor based on a glassy carbon electrode modified with a reduced graphene oxide and palladium nanoparticles composite. Microchimica Acta, 180, 1037-1042.

Pan, Q.M., Wang, Z.J., Liu, J., Yin, G.P. ve Gu, M., 2009. PbO@C core-shell nanocomposites as an anode material of lithium-ion batteries. Electrochem. Commun., 11, 917-920.

Parveen, A., Dashpande, R., Ahmed, S. ve Roy, A.S., 2013. Synthesis, characterisation, and DC conductivity of polyaniline-lead oxide composites. Chem. Pap., 67, 350-356.

Ramesha, G.K. ve Sampath, S., 2011. In-situ formation of graphene-lead oxide composite and its use in trace arsenic detection. Sensor.Actuat.B-Chem., 160, 306-311.

Sajadi, S.A.A., 2011. A comparative investigation of lead sulfate and lead oxide sulfate study of morphology and thermal decomposition. American Journal of Analytical Chemistry, 2, 206-211.

Shahid, M., Hamid, M., Mazhar, M., Akhtar, J., Zeller, M. ve Hunter, A.D., 2011. Crystalline $\mathrm{Cu}-\mathrm{PbO}$ ceramic composite thin films from $\mathrm{Pb}$ 2(OAc)(4)(mu-O)(3)Cu-6 (dmae)(4)Cl-4 center $\operatorname{dot}\left(\mathrm{C}_{7} \mathrm{H}_{8}\right)$ center dot $1.7\left(\mathrm{H}_{2} \mathrm{O}\right)$. Inorg. Chem. Commun., 14, 288-291.

Stillman, R., Robins, R. ve Skyllas-Kazacos, M., 1984. Quantitative X-Ray-Diffraction Analysis of Alpha-Pbo Beta-Pbo in Lead Acid Battery Primary Oxide. J. Power Sources 13, 171-180.

Sun, C., Lee, H., Yang, J. ve Wu, C., 2011. The simultaneous electrochemical detection of ascorbic acid, dopamine, and uric acid using graphene/size-selected $\mathrm{Pt}$ nanocomposites. Biosens. Bioelectron., 26, 3450-3455.

Teymourian, H., Salimi, A. ve Khezrian, S., 2013. $\mathrm{Fe}_{3} \mathrm{O}_{4}$ magnetic nanoparticles/reduced graphene oxide nanosheets as a novel electrochemical and bioeletrochemical sensing platform. Biosensors and Bioelectronics, 49, 1-8.

Velayutham, D. ve Noel M., 1992. Preparation of a Polypyrrole Lead Dioxide Composite Electrode for Electroanalytical Applications. Talanta, 39, 481-486.

Wang, C., Du, J., Wang, H., Zou, C., Jiang, F., Yang, P. ve Du, Y., 2014. A facile electrochemical sensor based on reduced graphene oxide and $\mathrm{Au}$ nanoplates modified glassy carbon electrode for simultaneous detection of ascorbic acid, dopamine and uric acid. Sens. Actuat. B: Chem., 204, 302-309.

Wang, Y., Li, Y., Tang, L., Lu, J. ve Li, J., 2009. Application of graphene-modified electrode for selective detection of dopamine. Electrochem. Commun., 11, 889-892.

Wang, Y., Wen, Z., Zhang, H., Cao, G., Sun, Q. ve Cao, J., 2016. CuO Nanorods-Decorated Reduced Graphene Oxide Nanocatalysts for Catalytic Oxidation of CO. Catalysts, 6, 214222.

Wang, Y.J., Panzik, J.E., Kiefer, B.ve Lee, K.K.M., 2012. Crystal structure of graphite under roomtemperature compression and decompression. Sci Rep-Uk, 2, 520.

Zhang, F., Li, Y., Gu, Y., Wang, Z. ve Wang, C., 2011. One-pot solvothermal synthesis of a $\mathrm{Cu}_{2} \mathrm{O}$ /graphene nanocomposite and its application in an electrochemical sensor for dopamine. Microchim Acta, 173,103-109.

Zhitomirsky, I., Galor, L., Kohn, A. ve Hennicke, H.W., 1995. Electrochemical Preparation of PbO Films, J. Mater. Sci. Lett., 14, 807-810. 